\title{
Polyphenolic Composition and Antioxidant Capacity of Indigenous Wild Dalmatian Sage (Salvia officinalis L.)
}

Maja Dent, * Danijela Bursać Kovačević, Tomislav Bosiljkov, Verica Dragović-Uzelac

\author{
Faculty of Food Technology and Biotechnology, University of Zagreb, Pierottijeva 6, 10000 Zagreb, Croatia \\ * Corresponding author's e-mail address: mfeges@pbf.hr
}

RECEIVED: March 15, 2017 * REVISED: July 15, 2017 * ACCEPTED: September 15, 2017

Abstract: The objective of our research was to study the effects of growing area on polyphenolic composition and antioxidant capacity on sage leaves extracts (Salvia officinalis L.). The evaluation considered naturally growing sage, indigenous to the Mediterranean part of Croatia, specifically from Pag, Pirovac, Brač and Lošinj areas. The results indicate that sage is rich with polyphenols, which show evident antioxidant capacity. Variations of total phenolic contents and their composition, as well as antioxidant capacity between sage extracts grown at the various growing area, were significant $(p \leq 0.05)$. Rosmarinic acid $(2460-3844 \mathrm{mg} / 100 \mathrm{~g})$ and lutolin-3-glucuronide $(634-840 \mathrm{mg} / 100 \mathrm{~g})$ were found to be the main polyphenols in sage leaves studied. A significant correlation between total phenols, particularly the most representative phenolic compound rosmarinic acid and luteolin-3-glucuronide, was verified. Principal component analyses (PCA) indicates that the composition of polyphenols in sage has no significant deviation. Nevertheless, the content of polyphenols differed depending on the location direction of the growing area and environmental factors.

Keywords: wild Dalmatian sage (Salvia officinalis L.), phenolic compounds, rosmarinic acid, luteolin-3-glucuronide, antioxidant capacity, growing area.

\section{INTRODUCTION}

$\mathbf{S}$ AGE (Salvia officinalis L.) is one of the most important aromatic plants, cultivated worldwide for its rich flavour, taste and biological properties as a source of secondary metabolites, including polyphenols and terpenes, which are economically important. ${ }^{[1-4]}$ The sage polyphenols are considered a source of natural antioxidants for the food and cosmetic industries, and have a greater benefit in comparison to synthetic ones because of their natural origin. ${ }^{[5]}$ Salvia officinalis $L$. is native and widely distributed in the Mediterranean region and grows naturally throughout the Croatian cost as a wild culture. Previous reports confirmed that high-quality sage can be obtained from Dalmatian growing areas. ${ }^{[6-8]}$

Numerous biological activities of sage are ascribed to complex mixtures of compounds belonging to diverse chemical families, including phenolic compounds with antioxidant activity, such as flavonoids, lignans and stilbenes, and simple phenolic acids, such as hydroxybenzoic and hydroxycinnamic acids. ${ }^{[8-10]}$ The presence of different phenolic acids (e.g. caffeic acid derivates and its oligomers, gallic, $p$-OH-benzoic, $p$ coumaric, syringic, vanillic and chlorogenic acids), as well as flavonoids as flavones (e.g. apigenin and luteolin glycosides and their corresponding constitute; 7-glycoside, 7glucuronide, 3-glucuronide, 6-hydroxyluteolin-7-glucoside) have already been confirmed in sage. ${ }^{[10-13]}$ The high content of polyphenols in sage is the result of good antioxidant properties and potential cumulative and synergistic effects of the diversity of major and minor phenolic components. ${ }^{[4]}$ The main antioxidant effect has been attributed to the presence of caffeic acid derivates and its oligomers, such as rosmarinic acid and flavones (glycosides of apigenin and luteolin). Besides antioxidant properties of the sage polyphenols, numerous researches have been devoted to their antifungal, antitumor, antiallergic, antibiotic and hypoglycaemic properties. . $^{[1,8,14]}$ 
It should be noted that, commercially, the quality of a sage extract is highly dependent on the amount of rosmarinic acid and their derivatives, ${ }^{[15]}$ which is generally the most abundant phenolic compound in sage. ${ }^{[11,16]}$

Several researchers ${ }^{[2,17,18]}$ considered that the phenolic content of a plant depends on different conditions, such as cultivation area, climatic conditions, harvest year, vegetation phase, genetic modifications, countries and geographical zones. Factors like human disturbance, herbivores pressure, competing plants, post harvesting treatments (dryness, distillation), as well as genetic outfits, affect the polyphenol production and composition and influence antioxidant performance. The accumulation of phenolics could be considered as a protective mechanism of plants against a hostile environment, or could occur as a response to the oxidative stress generated by the formation of reactive oxygen species in severe environment conditions (salinity, high temperature and drought). ${ }^{[4]}$ Except environmental conditions, genetic control is the primary factor in determining the amount of phenols in plant. The amounts of polyphenols in Thymus species planted on the same locality in Hungary vary due to different genetic features. ${ }^{[19]}$ The variation in amounts of individual phenols in Salvia species is affected by the instability of some phenolic compounds influenced by different environmental factors. A similar phenolic profile was observed within each studied Salvia species, where estimated concentrations of the majority of identified compounds varied significantly according to the gowning area. ${ }^{[3]}$ Besides harvesting year, it has been observed that different times of day when sage is harvested also have an influence on the phenolic composition and antioxidant activity of the sage. Other factors such as phenological stages and phenophase in which the leaves were collected make a significant difference to the phenolic composition of sage extracts and, consequently, their biological activity. Also, the phenolic accumulation detected during plant fruiting was concomitant with the temperature increase in the harvesting experimental field. Furthermore, different quantitative distribution of phenolic compounds in Salvia species was detected across various geographic areas. ${ }^{[3]}$ Therefore, the highest biological potential of sage could be achieved through selection of breeding areas of wild sage and by defining optimal growing conditions for cultivated sage.

In this study, sage leaves from four geographical areas were analysed in order to acquire total and individual phenolic compounds, as well as their antioxidant capacity, and to evaluate the significance of changes as a result of geographic origin and environmental factors. Data was analysed using Principal Component Analysis (PCA). Therefore, the main aim of this research was to determine the effect of the different growing areas (Pag, Pirovac, Brač and Lošinj) in Croatia on the composition and content of phenolic compounds (total and individual) in wild Dalmatian sage (Salvia officinalis L.).

\section{EXPERIMENTAL}

\section{Chemicals}

Ethanol, sodium carbonate and sodium nitrite were purchased from Gram-mol (Croatia). Folin Ciocolateu reagents, apigenin-7-glucoside, luteolin-3-glucoside, rosmarinic, caffeic, gallic, vanillic and siringinic acid were purchased from Sigma (Steinheim, Germany). Methanol (HPLC grade) was purchased from J. T. Baker (Holand).

\section{Plant Material}

The leaves of wild Dalmatian sage (Salvia officinalis L.) were collected at the four wild field sites in the Mediterranean region of Croatia. The sage was harvested in the same time of day, in the evening. The fields were located in four different parts of Croatian coast, from north to south (Lošinj, Pag, Pirovac, Brač). The plant material was dried immediately after harvesting. Then, the dry plant materials were packed in polyethylene bags and kept in a dark, dry and cool place. Before being used, the plant material was crushed using house blender (Mixy, Zepter International) and then used for extraction.

\section{Climatic Data}

Climatic data in the growing area was provided by the weather station DHMZ (Meteorological and Hydrological Service of Croatia, DHMZ) and were recorded daily at the weather station in Mali Lošinj, Pag, Šibenik and Brač. PCA analysis is based on the daily average maximum and minimum temperatures and mean daily rainfall through the month detected in observed year.

\section{Extraction Procedure}

$1 \mathrm{~g}$ of crushed dried sage leaves was extracted with $20 \mathrm{~mL}$ of $30 \%$ aqueous ethanol solvent $(v / v)$. Extraction was performed at $60{ }^{\circ} \mathrm{C}$ in a water bath (Memmert WB14, SV1422, Schwabach, Germany) for 30 minutes. The extracts were filtered through Whatman No. 40 filter paper (Whatman International Ltd., Kent UK) using a Buchner funnel, and filtrates were adjusted to $25 \mathrm{~mL}$ in a volumetric flask with extract solvent. Obtained polyphenolic extracts were used for determination of total polyphenols (TP), total flavonoids (FL) and antioxidant capacity (AOC) spectrophotometrically and individual polyphenols using HPLC coupled with UV/VIS PDA detector. The extracts were stored at $-18{ }^{\circ} \mathrm{C}$ until analyses (no more than 7 days). Each extract was carried out in triplicate. 


\section{Total Polyphenols (TP)}

Determination of total polyphenols was done according to a Folin-Ciocolateu colorimetric method as described in Singleton and Rossi. ${ }^{[20]}$ The extract was appropriate diluted and then oxidized with $1.25 \mathrm{~mL}$ freshly diluted $0.2 \mathrm{M}$ FolinCiocalteu reagent. This reaction was neutralized by adding $3.75 \mathrm{~mL}$ of saturated sodium carbonate solution. After 30 min incubation in a water bath at $50{ }^{\circ} \mathrm{C}$, absorbance readings were performed at $765 \mathrm{~nm}$ using a UV-VIS spectrophotometer (UV, UNICAM HELIOS $\beta$ ). Quantification of TP was made by using a calibration curve of the rosmarinic acid, which was prepared by the diluting stock standard in methanol solvent to yield 50 to $500 \mathrm{mg} / \mathrm{L}$. The results were calculated according to calibration curves for rosmarinic acid and the TP mass fraction, derived from triplicate analyses and expressed as $\mathrm{mg}$ equivalent of rosmarinic acid (RAE) per $100 \mathrm{~g}$ dry matter. Values were expressed as means $(n=3) \pm$ standard deviations (S.D.).

\section{Total Flavonoids}

Total flavonoids of the extracts were measured using a colorimetric assay with aluminium chloride developed by Zhishen et al. ${ }^{[21]} 1 \mathrm{~mL}$ of the sage extract was added to a 10 $\mathrm{mL}$ volumetric flask. Distilled water was added to make a volume of $4 \mathrm{~mL}$. At zero time, $0.3 \mathrm{~mL}$ of $5 \%(w / v)$ sodium nitrite was added to the flask. After $5 \mathrm{~min}, 3 \mathrm{~mL}$ of $10 \%$ $(w / v)$ aluminium chloride and then after $6 \mathrm{~min}, 2 \mathrm{~mL}$ of $1 \mathrm{M}$ sodium hydroxide were added to the mixture and filled with distilled water up to $10 \mathrm{~mL}$. Finally, a $10 \mathrm{~mL}$ aliquot was taken, centrifuged for $10 \mathrm{~min}$, and assayed for total flavonoids. Absorbance readings were performed using a UV-VIS spectrophotometer (UV, UNICAM HELIOS $\beta$ ) at 510 $\mathrm{nm}$. Quantification of total flavonoids was made by using the calibration curve of rutin, which was prepared by diluting stock standard with methanol solvent to yield 50 to $250 \mathrm{mg}$ per $100 \mathrm{~mL}$ of flavonoids. Flavonoid content was expressed as mg equivalent of rutin (RE) per $100 \mathrm{~g}$ dry matter, derived from triplicate analyses. Values were expressed as means $(n=3) \pm$ standard deviations (S.D.).

\section{DPPH Scavenging Capacity}

Antioxidant capacity of sage extracts was evaluated according to the DPPH (2,2'-diphenyl-1-picrylhydrazyl) free radical scavenging method to Brand-Williams. ${ }^{[22]} 1 \mathrm{~mL}$ of phenolic extracts was added to $1 \mathrm{~mL}$ of DPPH methanolic solution $(0.5 \mathrm{mM})$ and $3 \mathrm{~mL}$ of methanol. The mixture was shaken vigorously and allowed to stand at room temperature in the dark for 20 minutes. Absorbance at 517 $\mathrm{nm}$ was measured using a spectrophotometer (UV, UNICAM HELIOS $\beta$ ) using methanol as a blank. Trolox (6hydroxy-2,5,7,8-tri-methyl-chroman-2-carboxylic acid) was used to prepare the calibration curve. Antioxidant capacity was expressed as $\mu \mathrm{mol}$ Trolox equivalents per $100 \mathrm{~g}$ dry matter of sage. All determinations were performed in triplicate. Values were expressed as means $(n=3) \pm$ standard deviations (S.D.).

\section{Feric Reducing Antioxidant Power (FRAP)}

The FRAP assay was carried out as described by Connor et al. ${ }^{[23]}$ The FRAP reagent was freshly prepared by mixing 300 $\mathrm{mM}$ sodium acetate in distilled water $\mathrm{pH} 3.6,20 \mathrm{mM}$ $\mathrm{FeCl}_{3} \cdot 6 \mathrm{H}_{2} \mathrm{O}$ in distilled water and $10 \mathrm{mM}$ 2,4,6-tri(2-pyridyl)s-triazine (TPTZ) in $40 \mathrm{mM} \mathrm{HCl}$ in the proportion of 10:1:1. An aliquot of $80 \mu \mathrm{L}$ of sample (with appropriate dilution) was added to $2080 \mu \mathrm{L}$ of FRAP reagent. The absorbance of the resulting solution was measured at $595 \mathrm{~nm}$ using a spectrophotometer (UV, UNICAM HELIOS $\beta$ ) after 5 min incubation at $37{ }^{\circ} \mathrm{C}$. The measurement was performed in triplicate. Fresh working solution of $20 \mathrm{mM} \mathrm{FeSO} \cdot 7 \mathrm{H}_{2} \mathrm{O}$ were used for calibration curve. FRAP values were expressed as $\mu \mathrm{mol} \mathrm{Fe}^{2+} / 100 \mathrm{~g}$ dry matter of sage. Values were expressed as means $(n=3) \pm$ standard deviations (S.D.).

\section{HPLC UV-PDA Analysis}

Individual phenolic compounds of sage were determined by HPLC using a Varian ProStar System (Varian Inc., Palo Alto, CA, USA) equipped with a ProStar Solvent Delivery Module 230, Injector Rheodyne 7125, ProStar 330 UV/VIS photo diode array detector. Chromatographic separation was performed on a reverse-phase Zorbax ODS C18 column ( $4.6 \mathrm{~mm} \times 250 \mathrm{~mm}, 5 \mu \mathrm{m}$ particle size) including Zorbax ODS C18 guard column ( $10 \mathrm{~mm} \times 4.6 \mathrm{~mm}, 5 \mu \mathrm{m}$ particle size) (Agilent Technologies, Palo Alto, CA, USA). The composition of solvents and gradient elution conditions had previously been described Dent et al. ${ }^{[5]}$ The following gradient of mobile phase $A$ ( $3 \%$ formic acid in acetonitrile) and mobile phase $B$ ( $3 \%$ formic acid in water) was used for the separation of polyphenols: commencing with $10 \% A$ in $B$, rising to $40 \% \mathrm{~A}$ after $25 \mathrm{~min}$, then to $70 \% \mathrm{~A}$ after $30 \mathrm{~min}$ and then to $10 \% \mathrm{~A}$ after $35 \mathrm{~min}$. The flow rate was set to $0.9 \mathrm{~mL} / \mathrm{min}$. Operating conditions were as follows: column temperature, $20{ }^{\circ} \mathrm{C}$, injection volume, $20 \mu \mathrm{L}$. Before injection, extracts were filtered through $0.45 \mu \mathrm{L}$ Nylon Membrane filter (Supelco, USA). Detection was performed with UV-PDA detector by scanning from 278 to $360 \mathrm{~nm}$. Identification of phenolic compounds in sage was made by comparison of retention times $\left(R_{t}\right)$, peak areas and UV spectra with those of authentic standards. Quantitative determinations were carried out using calibration curves of the standards. Phenolic acids (rosmarinic, caffeic, vanilic and siringinic acid) and flavonoids (luteolin-3-glucoside and apigenin-7-glucoside) were used as standards. Calibration curve of the phenolic acids and flavonoids standards were made by diluting stock standards (concentration 0.5-2 $\mathrm{mg} / \mathrm{mL}$ ) in methanol to yield $0.001-0.02 \mathrm{mg}$ per $\mathrm{mL}$. The 
Table 1. Total phenols, total flavonoids and the most represented phenolic acid and flavonoid in the sage extracts from the leaves naturally growing in Mediterranean part of the Republic of Croatia. Results are expressed as mg/100 g dm

\begin{tabular}{|c|c|c|c|c|c|c|}
\hline Phenolics & $\begin{array}{l}\omega \text { (Total phenols)/ } \\
\text { (mg RA/100g dm) }\end{array}$ & $\begin{array}{c}\omega \text { (Flavonoids)/ } \\
\text { (mg RE/100g dm) }\end{array}$ & $\begin{array}{c}\omega(\text { Rosmarinic acid)/ } \\
(\mathrm{mg} / 100 \mathrm{~g} \mathrm{dm})\end{array}$ & $\begin{array}{l}\omega(\text { Luteolin-3- } \\
\text { glucuronide)/ } \\
\text { (mg/100g dm) }\end{array}$ & $\begin{array}{c}D P P H / \\
(\mu \mathrm{mol} T E / 100 \mathrm{~g})\end{array}$ & $\begin{array}{c}\text { FRAP / } \\
\left(\mu \mathrm{mol} \mathrm{Fe} \mathrm{Fe}^{2+} / 100 \mathrm{~g}\right)\end{array}$ \\
\hline \multicolumn{7}{|c|}{ Growing area } \\
\hline Pag & $6384.00 \pm 21.21 \mathrm{a}$ & $1905.50 \pm 26.16 \mathrm{a}$ & $3474.00 \pm 19.80 \mathrm{a}$ & $776.00 \pm 16.97 \mathrm{a}$ & $173.48 \pm 0.42 \mathrm{a}$ & $562.68 \pm 13.87 a$ \\
\hline Pirovac & $5502.00 \pm 14.44 \mathrm{~b}$ & $1835.00 \pm 42.43 \mathrm{a}$ & $2571.00 \pm 2.83 \mathrm{~b}$ & $642.50 \pm 13.44 b$ & $170.46 \pm 0.34 a$ & $457.23 \pm 2.66 \mathrm{a}$ \\
\hline Brač & $5514.50 \pm 144.96 \mathrm{~b}$ & $1199.50 \pm 19.09 \mathrm{~b}$ & $2460.00 \pm 7.07 c$ & $634.50 \pm 38.89 b$ & $170.92 \pm 1.35 \mathrm{a}$ & $425.81 \pm 23.40 \mathrm{a}$ \\
\hline Lošinj & $7787.50 \pm 389.62 \mathrm{c}$ & $1797.50 \pm 23.33 \mathrm{a}$ & $3844.00 \pm 26.87 d$ & $840.00 \pm 26.87 a$ & $175.46 \pm 0.42 \mathrm{a}$ & $604.06 \pm 9.60 \mathrm{a}$ \\
\hline
\end{tabular}

results were calculated according to calibration curves of the phenolic acids and flavonoids, and mass fraction, derived from triplicate analyses and were expressed as $\mathrm{mg}$ phenolic acids or flavonoids equivalent per $100 \mathrm{~g}$ dry matter. Values were expressed as means $(n=3) \pm$ standard deviations (S.D.). Salvianolic K and salvianolic I acid, methyl rosmarinate were quantified as the equivalent of rosmarinic acid. 6-hydroksyluteolin-7-glucoside, luteolin-7glucuronide and luteolin-3-glucuronide were quantified as the equivalent of luteolin-3-glucoside and apigenin-7glucuronide as the equivalent of apigenin-7-glucoside.

\section{Statistical Analysis}

The experimental data was subjected to analysis of variance (ANOVA) using "Statistica" 10.0 software. Tukey's HSD was used to determine whether there are any significant differences between means (post-hoc); $p$ values less than 0.05 were considered statistically significant. Multivariate technique - Principal Component Analyses (PCA) was performed using "Statistica" 10.0 software. Synergistic influence of observed parameters is represented with 2D graphs. Arranged score plot is presented in for four different areas.

\section{RESULTS AND DISCUSSION}

The obtained results shown in Table 1 indicate a variation in polyphenols of sage (Salvia officinalis L.) growing wild in different areas. The differences are, apparently, related to the distinct habitats where the plants are grown and to their genetic outfits. The differences in the mass fraction of polyphenols could be related to the impact of climate and ecological characteristics, geographical coordinates, soil with aerial parts of the plants, and time of harvest. ${ }^{[2]}$ Similarly, the mass fraction of phenolic compounds in sage cultivated in different countries varied like those in Finland (166 mg/g), ${ }^{[24]}$ Tunisia (158.79, $\left.161.37 \mathrm{mg} / \mathrm{g}\right)^{[3]}$ and Greece (63.7 $\mathrm{mg}$ to $144 \mathrm{mg} / \mathrm{g}$ ), ${ }^{[25]}$ all of which corresponds with our results. The Mediterranean part of the Republic of Croatia has a mild Mediterranean climate. The geographical area of
Lošinj, with the highest measured mass fraction of polyphenols, proved to be the area with the least fluctuation in average daily temperature and with a small amount of rainfall throughout the year. Polyphenols seem to be very sensitive to environmental and climatic conditions. Weather conditions reflected the specific orographic position (distance from the sea, elevation above the sea level, number of sunny days, exposure to the wind). Stress factors such as drought, salinity, cold, soil characteristic etc. may increase secondary metabolites synthesis in plants and could have caused a decrease in phenolic content for the growing area. ${ }^{[26]}$ Total phenolic content of sage extracts was found to be in a range of 5502.50 to $7787.50 \mathrm{mg} / 100 \mathrm{~g} \mathrm{dm}$, with lowest amounts measured in samples from Pirovac and highest amounts from those in Lošinj. As it can be seen, significant differences $(p \leq 0.05)$ in the mass fraction of total phenols were observed among the growing areas. The flavonoid contents of sage extracts ranged between 1119.50 to $1905.50 \mathrm{mg} / 100 \mathrm{~g} \mathrm{dm}$, depending on the growing area. The highest flavonoid content was found in the growing area of Pag, while in other areas (Pirovac, Lošinj and Brač) it was observed in lower content $(p \leq 0.05)$. From the obtained results it can be see that growing areas (Pag, Pirovac and Lošinj) showed significant differences between themselves, but only the growing area of Brač indicated a significant impact on a lower mass fraction of flavonoids ( $p \leq 0.05)$. According to these results, we can conclude that mass fraction of total phenols was considerably more affected by the growing area in relation to flavonoids in sage. PCA showed the variability among the mass fraction of total phenols and flavonoids to the weather data (average temperature and rainfall) of the different growing area. Obtained results are represented with $98.94 \%$ of the sum of variance ( $85.53 \%$ and $13.41 \%$ resp. Figure 1$)$. It can be seen that temperatures between $14.81-15.79{ }^{\circ} \mathrm{C}$ and rainfalls between $68.47-75.62 \mathrm{~mm}$ have a significant influence on the mass fraction of observed compounds at the island of Lošinj area. Flavonoids content is significantly increased in the direction of island Pag (Figure 1). 
a)

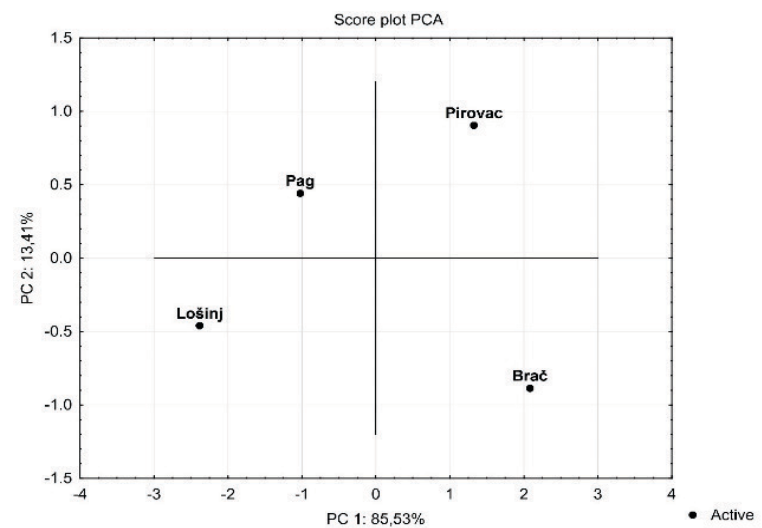

c)

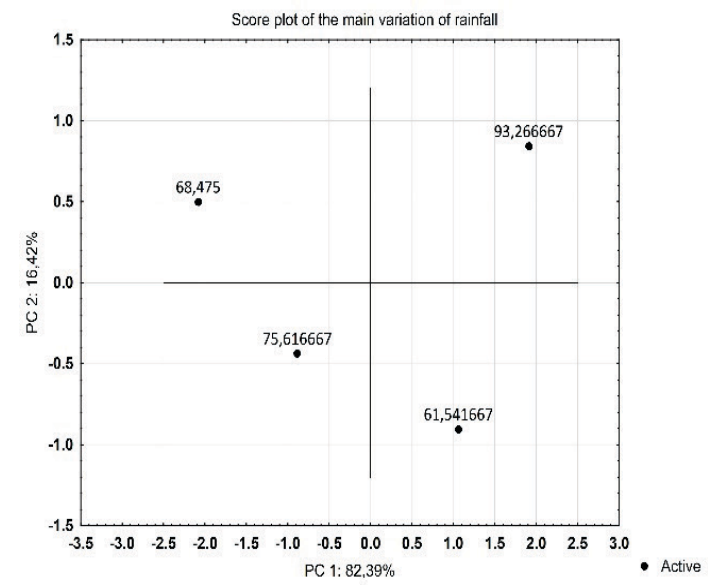

b)

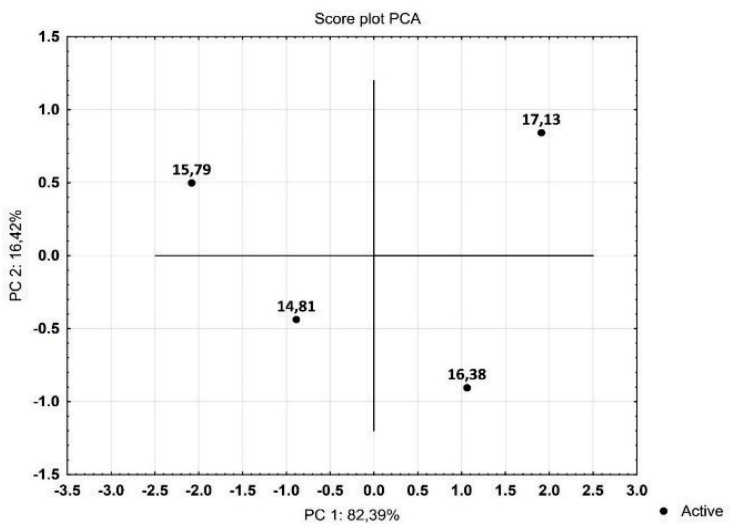

d)

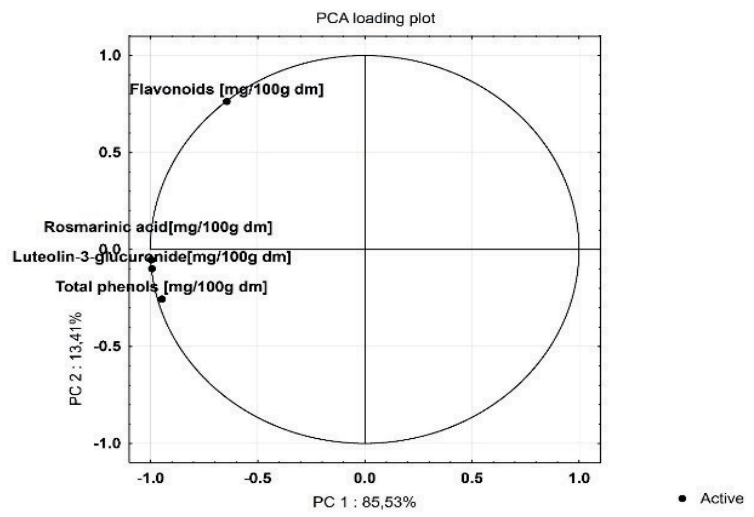

Figure 1. PCA loading plot and score plot of the different growing areas of sage (Salvia officinalis L.) (a) based on the average daily temperature (b) and sum of rainfall (c) based on common phenolic composition (total phenols, flavonoids, rosmarinic acid and luteolin-3-glucuronide) (d)

The phenolic profile of wild Dalmatian sage (Salvia officinalis L.) is shown in Table 2 . The data has enabled the identification of thirteen phenolic compounds and their glycosides in all sage extracts, including seven phenolic acids (vanilic, caffeic, syringic, rosmarinic, salvianolic K, I acids, methyl rosmarinate) and six flavonoids (6-hydroxyluteolin-7-glucoside, luteolin and their 7-glucuronide, 3-glucuronide, 7-glucoside; apigenin and their 7glucuronide and 7-glucoside). There were no differences in the composition of phenolic acids and flavone glycosides depending on the growing area, while a significant difference was found in the amounts of polyphenols. As seen in other relevant literature, ${ }^{[2,4,7,12,27]}$ the phenolic compounds reported in this study were previously identified in several Salvia species. The caffeic acid dimmer, rosmarinic acid is, generally, the most abundant phenolic compound in Lamiaceae. ${ }^{[12]}$ Among the identified phenolic compounds, rosmarinic acid was present in the largest amounts in sage extracts for all four growing areas, in a mass fraction range from 2460 to $3844 \mathrm{mg} / 100 \mathrm{~g} \mathrm{dm}$. Mass fraction of rosmarinic acid in total acid content in all Dalmatian wild sage leaf extracts ranged from $91.83 \%$ to $94.40 \%$, which corresponds with results from other authors who reported similar ranges $(94.54 \%$ to 98.38 \%). ${ }^{[7]}$ Samples collected in Lošinj ( $3844 \mathrm{mg} / 100 \mathrm{~g} \mathrm{dm}$ ) showed the highest mass fraction of rosmarinic acid. However, those collected in Brač ( $2460 \mathrm{mg} / 100 \mathrm{~g} \mathrm{dm}$ ) were characterized by the lowest mass fraction. Growing area showed a significant impact on mass fraction of rosmarinic acid as an abundant phenolic compound in sage extracts the highest amount measured was found in samples obtained in Lošinj, while a slightly lower amount was found in those obtained in Brač $(p \leq 0.05)$ (Table 1). PCA showed significant variability in the mass fraction of rosmarinic acid depending on the growing area. Obtained results are represented with $86.35 \%$ of the sum of variance $(50.52 \%$ 
Table 2. Phenolic composition identified in the sage extracts from the leaves naturally growing in Mediterranean part of the Republic of Croatia. Contents of polyphenols are expressed as milligrams per $100 \mathrm{~g}$ dry matter of sage

\begin{tabular}{ccccc}
\hline Growing area & Pag & Pirovac & Brač & Lošinj \\
\hline$\omega$ (Phenolics)/(mg/100g dm) & & & & \\
Phenolic acids & & & & \\
Vanilic acid & $29.04 \pm 3.80$ & $36.15 \pm 3.42$ & $22.10 \pm 3.74$ & $29.31 \pm 6.16$ \\
Caffeic acid & $31.51 \pm 2.76$ & $24.45 \pm 3.02$ & $37.62 \pm 2.03$ & $31.08 \pm 2.99$ \\
Syringic acid & $64.30 \pm 1.78$ & $97.12 \pm 1.63$ & $74.19 \pm 10.99$ & $111.47 \pm 10.56$ \\
Rosmarinic acid & $3474.00 \pm 19.80$ & $2571.00 \pm 2.83$ & $2460.00 \pm 7.07$ & $3844.00 \pm 26.87$ \\
Salvianolic K acid & $47.50 \pm 4.25$ & $43.52 \pm 12.59$ & $46.42 \pm 4.78$ & $54.18 \pm 1.25$ \\
Salvianolic I acid & $22.28 \pm 2.41$ & $15.32 \pm 12.44$ & $20.56 \pm 8.89$ & $12.17 \pm 1.78$ \\
Methyl rosmarinat & $12.32 \pm 7.98$ & $15.48 \pm 9.95$ & $20.12 \pm 10.12$ & $28.29 \pm 1.60$ \\
Flavonoids & & & & \\
6-Hydroxsyluteolin-7-glucoside & $169.29 \pm 10.89$ & $158.90 \pm 15.82$ & $174.54 \pm 10.74$ & $200.17 \pm 13.16$ \\
Luteolin-7-glucuronide & $365.21 \pm 20.01$ & $148.55 \pm 12.96$ & $416.25 \pm 11.55$ & $348.71 \pm 3.80$ \\
Luteolin-7-glucoside & $127.78 \pm 12.78$ & $154.26 \pm 1.01$ & $216.56 \pm 10.71$ & $232.42 \pm 11.98$ \\
Luteolin-3-glucuronide & $776.00 \pm 16.97$ & $642.50 \pm 13.44$ & $634.50 \pm 38.89$ & $840.00 \pm 26.87$ \\
Apigenin-7-glucuronide & $111.10 \pm 1.63$ & $167.55 \pm 10.74$ & $101.10 \pm 5.89$ & $122.52 \pm 7.79$ \\
Apigenin-7-glucoside & $155.21 \pm 12.71$ & $100.14 \pm 10.55$ & $86.11 \pm 7.22$ & $143.40 \pm 8.47$ \\
\hline
\end{tabular}

and $35.83 \%$ resp. Figure 2). It can be seen that growing area has a significant influence on the mass fraction of phenolic acids, especially rosmarinic acid and other caffeic dimer acids (salvianolic $\mathrm{K}$ acid and methyl rosmarinat) at the area of island Lošinj (Figure 2).

These results agreed with data reported by others who also determined the rosmarinic acid in sage in similar amounts. Generalić et al. ${ }^{[6]}$ detected rosmarinic acid in Dalmatian sage (6109 to $19.347 \mathrm{mg} / \mathrm{L}$ ), Koşar et al. ${ }^{[27]}$ (97.9 $\mathrm{mg} / \mathrm{g}$ ) in sage harvested in Finland, and Pizzale et al. ${ }^{[28]}$
( 21.9 to $81.8 \mathrm{mg} / \mathrm{g}$ ) in sage harvested at different locations within northern Italy, by using methanol as the extraction solvent. The proportion of other phenolic acids was significantly smaller than that of rosmarinic, in the following order: syringic $>$ salvianolic K $>$ caffeic $>$ vanilic $>$ salvianolic I. After the quantitative analysis, we have established that the occurrence of rosmarinic acid was general, with rather low variability between growing areas. According to these results, we can say that the mass fraction of rosmarinic acid was much more affected by the growing area in relation to a)

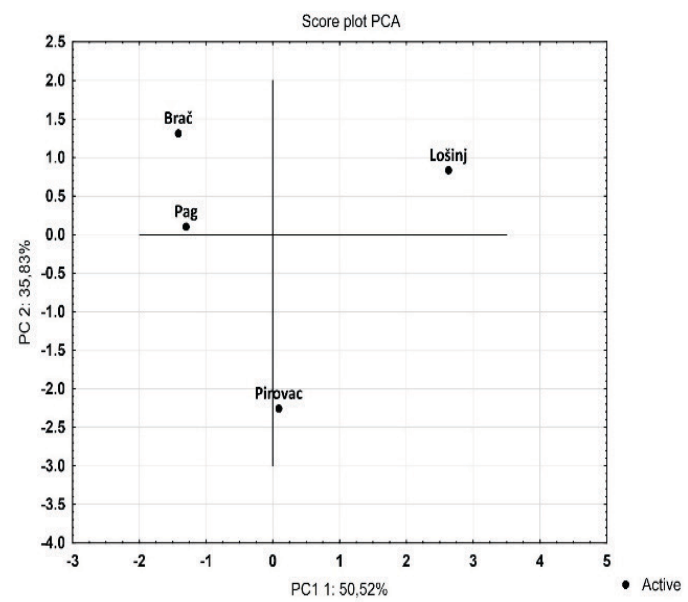

b)

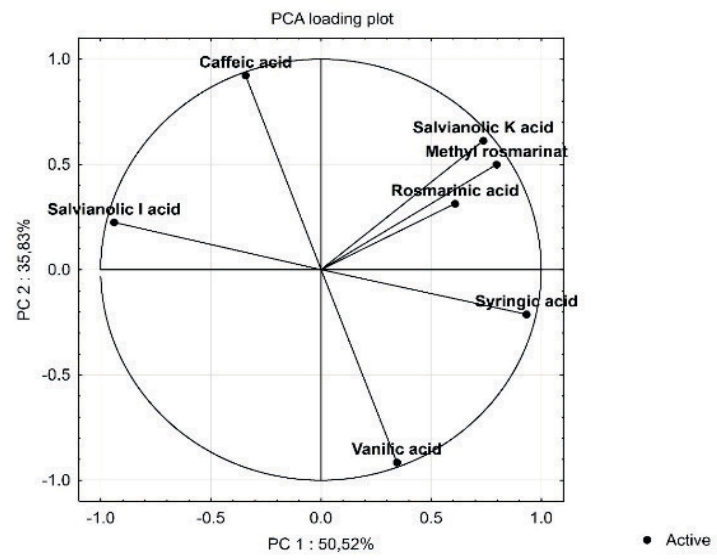

Figure 2. PCA loading plot and score plot of the different growing areas of sage (Salvia officinalis L.) (a) based on common phenolic acids (vanilic acid, caffeic acid, syringic acid, rosmarinic acid, salvianolic $\mathrm{K}$ acid, salvianolic I acid and methyl rosmarinate) (b). For further details, cf. Table 2. 
a)

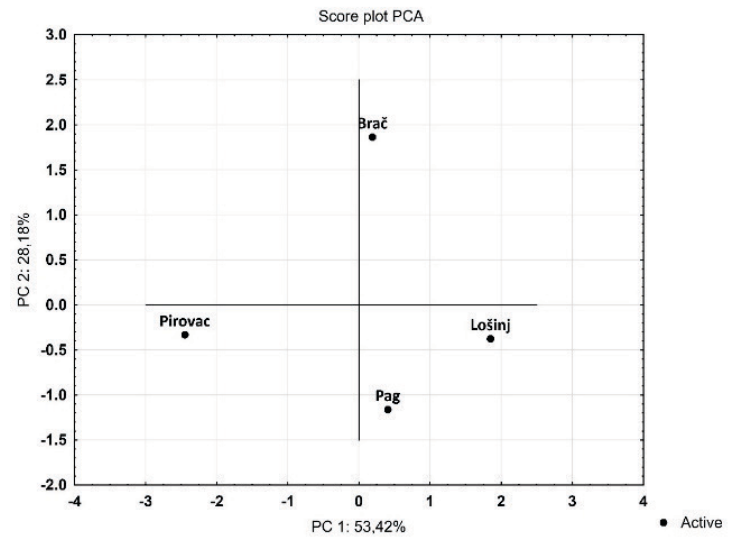

b)

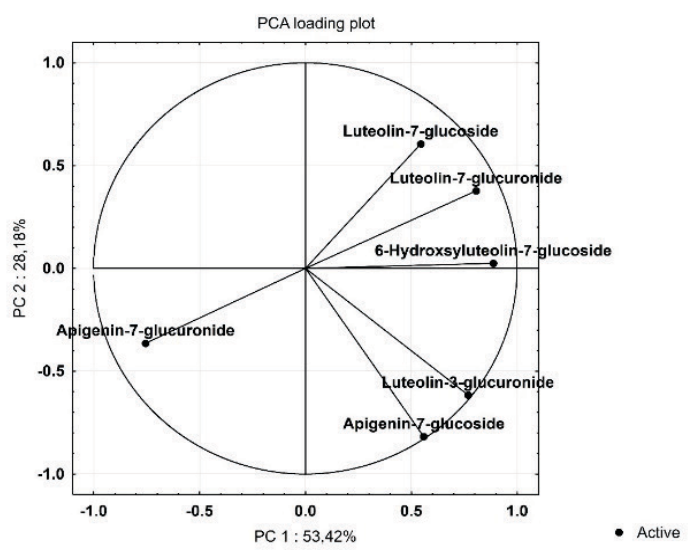

Figure 3. PCA loading plot and score plot of the different growing areas of sage (Salvia officinalis L.) (a) based on common flavone glycosides (6-hydroxsyluteolin-7-glucoside, luteolin-7-glucuronide, luteolin-7-glucoside, luteolin-3-glucuronide, apigenin-7-glucuronide and apigenin-7-glucoside) (b). For further details, cf. Table 2.

the mass fraction of other phenolic acids in sage. Research results are in accordance with literature data, stating that caffeic acid plays a central role in the biochemistry of Lamiaceae, while free caffeic acid was lower compared to syringic and rosmarinic acid. ${ }^{[7,12]}$ Except phenolic acid, wild Dalmatian sage also contained a wide range of flavonoids in the range from $20.07 \%$ to $29.06 \%$, depending on the growing area. A similar content of flavonoids in sage was obtained in the range from $22 \%$ to $40 \%$ during the year, depending on phenophase. ${ }^{[7]}$ Flavonoids detected in sage extracts mainly belong to the group of flavones (luteolin and apigenin glycosides). From the group of flavones, apigenin and luteolin glycosides were present in all of our sage extracts. Luteolin-3-glucuronide ranged between 634.50 (Brač) to 840 (Lošinj) mg/100 g dm. Sage extracts from Pag and Lošinj, contained higher amounts of this luteolin glycoside than those from Brač and Pirovac, but also other luteolin (6-hydroxyluteolin-7-glucoside, luteolin and their 7-glucuronide, 3-glucuronide, 7-glucoside) and apigenin (7-glucuronide, 7-glucoside) glycosides in our sage extracts. Growing area showed a significant impact on mass fraction of luteolin-3-glucuronide, with samples from Lošinj showing the highest mass fraction, and samples from Pag, Brač and Pirovac showing lower amounts ( $p \leq 0.05)$ (Table 1). PCA showed significant variability in the mass fraction of apigenin and luteolin glycosides depending on the growing area. Obtained results are represented with $81.60 \%$ of the sum of variance $(53.42 \%$ and $28.18 \%$ resp. Figure 3). It can be seen that growing area has a significant influence on the mass fraction of luteolin-3-glucuronide and apigenin-7-glucoside at the area of island Lošinj and Pag (Figure 3).
The presence of both compounds in sage leaves has been reported by different authors. ${ }^{[28-30]}$ From the thirteen polyphenols identified, rosmarinic acid and luteolin-3glucuronide were the most abundant phenolic acid and flavonoid found in all the samples. Considering all the results, HPLC analysis showed that sage extracts do not differ in the composition of phenolic compounds depending on the growing area. Differences were observed in the mass fraction of individual phenolic acids and flavone glycosides within each sample by growing area. Differences in the yield of polyphenols could be explained by different environmental factors, such as growing conditions, harvesting, processing, among other factors that can directly interfere with the levels of polyphenols, which is in accordance with results of other authors. ${ }^{[4,19]}$ Sage extracts possess significant antioxidant activities due to the high content of polyphenols, ${ }^{[2]}$ especially caffeic acid derivates like rosmarinic acid as the most abundant phenolic acid in Salvia species. ${ }^{[7,12]}$ Many studies on antioxidant compounds of the Lamiaceae family focus on phenolic diterpenes, flavonoids and phenolic acids. ${ }^{[7,9,28,30]}$ and their biological activities including antioxidant, antitumor and antiviral activity. ${ }^{[8,14]}$

According to results shown in Table 1, it is evident that all extracts show good antioxidant properties, but there are no significant differences between growing areas. The results obtained from total and individual phenols and DPPH and FRAP assays show a high degree of correlation (Table 3). The highest correlation was observed between the total phenols, rosmarinic acid, hydroxycinnamic acids and luteolin-3-glcuronide with two applied assays, as well between total and individual phenols, especially rosmarinic 
Table 3. Linear correlations coefficients among basis total and individual phenols, flavonoids and antioxidant capacity

\begin{tabular}{cccc}
\hline & DPPH & FRAP & Total phenols \\
\hline Total phenols & 0.9855 & 0.9105 & - \\
Rosmarinic acid & 0.9645 & 0.9904 & 0.9418 \\
Luteolin-3-glucuronide & 0.9882 & 0.9832 & 0.9706 \\
Hydroxycinnamic acids & 0.9636 & 0.9884 & 0.9420 \\
Hydroxybenzoic acids & 0.4685 & 0.3098 & 0.4550 \\
Luteolin glycosides & 0.5297 & 0.7029 & 0.9706 \\
Apigenin glycosides & 0.8480 & 0.8436 & 0.8324 \\
\hline
\end{tabular}

acid and luteolin-3-glucuronide. There was no significant correlation between hydroxybenzoic acids and total phenols, as well for the DPPH and FRAP assay. This is coherent with the results of the HPLC analysis (Table 2), which confirmed the presence of large amounts of strong antioxidants from caffeic acid derivates and luteolin glycosides, especially for Lošinj growing area. Samples from the Lošinj area gave the best results, which implies a higher free radical scavenging capacity of polyphenols present in this extract, and can be linked to the significantly higher content of rosmarinic acid and certain flavone glycosides. The high contents of polyphenols and a significant linear correlation between the values of concentration of polyphenols and antioxidant capacity indicate that these compounds contribute to the strong antioxidant capacity of plant extracts, which is in accord with other findings. ${ }^{[2,5,8,12]}$ From the results obtained in this research, we can conclude that antioxidant capacity in sage extracts is significantly correlated with the amount of polyphenols in the growing area.

This study showed a significant variation between four growing areas in terms of total and individual polyphenols as well as in antioxidant capacity of sage. Furthermore, mass fraction of polyphenols in sage was significantly affected by the growing area. Even though these plants grow in similar growing areas, the differences detected in the amounts of polyphenols might be due to different bioclimatic parameters. The phenolic profiles of sage collected in the Mediterranean region of the Republic of Croatia suggest that the mass fraction of polyphenols are influenced by the local environmental growth conditions, and they could be considered as a promising growing area that could be exploited in obtaining natural antioxidants as an alternative to the synthetic ones. From a chemical and biodiversity perspective, sage from the Mediterranean part of the Republic of Croatia might be considered as a significant natural source of antioxidants for food development. The results showed the importance of comparing and exploring of polyphenolic content and antioxidant performance of sage growing in various regions, to select plants with optimal contents of polyphenols.
Acknowledgment. The financial support of the Ministry of Science, Technology and Sport of the Republic of Croatia (Grant No. 058-00000-3488) is gratefully acknowledged. The authors are deeply grateful to Meteorological and Hydrological Service of the Republic of Croatia for weather information.

Appendixes. TP, total phenols; FL, total flavonoids; AOC, antioxidant capacity; PCA, Principal Component Analysis

\section{REFERENCES}

[1] A. Russo, C. Formisano, D. Rigano, F. Senatore, S. Delfine, V. Cardile, S. Rosselli, M. Bruno, Food. Chem. Toxicol. 2013, 55, 42.

[2] M. B. Farhat, A. Landoulsi, R. Chaouch-Hamada, J. A. Sotomayor, M. J. Jordan, Ind. Crop. Prod. 2013, 49, 373.

[3] M. B. Farhat, R. Chaouch-Hamada, J. A. Sotomayor, A. Landoulsi, M. J. Jordán, Ind. Crop. Prod. 2014, $54,78$.

[4] M. S. Stanković, Kragujevac J. Sci. 2011, 33, 63.

[5] M. Dent, V. Dragović-Uzelac, M. Penić, M. Brnčić, T. Bosiljkov, B. Levaj, Food Technol. Biotechn. 2013, 51(1), 84.

[6] I. Generalić, D. Skroza, I. Ljubenkov, A. Katalinić, F. Burčul, V. Katalinić, Food. Chem. 2011, 127, 427.

[7] V. Katalinić, M. Miloš, M. Jukić, Food. Chem. 2006, 94, 550.

[8] M. Kivlompolo, T. Hyötyläinen, J. Chromatogr. A 2007, 1145, 155.

[9] Y. Lu, L. Yeap Foo, Phytochem. 2000, 55, 263.

[10] Y. Lu, L. Yeap Foo, Food. Chem. 2001, 75, 197.

[11] Y. Lu, L. Yeap Foo, Phytochem. 2002, 59, 117.

[12] N. E. Durling, O. J. Catchpole, J. B. Grey, R. F. Webby, K. A. Mitchell, L. Y. Foo, N. B. Perry, Food. Chem. 2007, 101, 1417.

[13] N. Martins, L. Barros, C. Santos-Buelga, M. Henriques, S. Silva, I. C. F. R. Ferreira, Food. Chem. 2015, 170, 378.

[14] N. Nakatani. Antioxidants from spices and herbs. In: Shahidi, F. (Ed.), Natural Antioxidants: Chemistry, Health Effects and Applications. AOSC Press, Champaign, 1997, pp. 64. 
[15] P. Putnik, D. Bursać Kovačević, M. Penić, M. Fegeš, V. Dragović-Uzelac, Microwave Assisted Extraction (MAE) of Dalmatian Sage Leaves for the Optimal Yield of Polyphenols: HPLC-DAD Identification and Quantification, Food Anal. Methods 2016, 9(8), 2385.

[16] G. Miliauskas, P. R. Venskutonis, T. A. van Beek, Food. Chem. 2004, 85, 231.

[17] J. J. Macheix, A. Fleurient, J. Billot. Phenolic compounds in fruit processing. In fruit phenolics. CRP Press, Boca Raton, FL, 1990, pp. 295.

[18] E. Tulukcu, H. Yalcin, I. Ozturk, O. Sagdic, Ind. Crop. Prod. 2012, 39, 69.

[19] B. Boros, S. Jakabova, A. Dornyei, G. Horvath, Z. Pluhar, F. Kilar, A. Felinger, J. Chromatogr. A 2010, 1217, 7972.

[20] V. L. Singleton, J. A. Rossi, Am. J. Enol. Viticult. 1965, 16, 144.

[21] J. Zhishen, T. Mengcheng, W. Jianming, Food. Chem. 1999, 64, 555.
[22] W. Brand-Williams, M.E. Cuvelier, C. Berset, Lebensm. Wiss. Technol. 1995, 28, 25.

[23] A. M. Connor, J. J. Luby, C. B. S. Tong, J. Amer. Soc. Hortic. Sci. 2002, 127, 238.

[24] H. J. D. Dorman, A. Peltoketo, R. Hiltunen, M. J. Tikkanen, Food. Chem. 2003, 83, 255.

[25] V. Papageorgiou, C. Gardeli, A. Mallouchos, M. Papaioannou, M. Komaitis, J. Agric. Food. Chem. 2008, 56 (16), 7254.

[26] I. B. Rebey, I. Jabri-Karoui, I. Hamrouni-Sellami, S. Bourgou, F. Limam, B. Marzouk, Ind. Crop. Prod. 2012, 36, 238.

[27] M. Koşar, H. J. D. Dorman, R. Hiltunen, Food. Chem. 2005, 91, 525.

[28] L. Pizzale, R. Bortolomeazzi, S. Vichi, E. Überegger, L. S. Conte, J. Sci. Food. Agri. 2002, 82, 1645.

[29] M. B. Hossain, C. Barry-Ryan, A. B. Martin-Diana, N. P. Brunton, Food. Chem. 2010, 123, 85.

[30] B. F. Zimmermann, S. G. Walch, L. N. Tinzoh, W. Stühlinger, D. W. Lachenmeier, J. Chromatogr. B 2011, 879, 2459. 